\title{
Man-tree metaphor in British linguoculture
}

\author{
Elena Abramova ${ }^{1,{ }^{*},}$ Elena Pavlycheva ${ }^{1}$, Olga Tarasova $^{1}$, and Lubov' Tsilenko ${ }^{1}$ \\ ${ }^{1}$ Moscow Region State University, 141014, Very Voloshinoi Str., 24, Mytishchi, Russia
}

\begin{abstract}
The tree has long been incorporated into human culture and is interpreted as compatible with a human being as a result of the man' cognizing the world. Thus, the tree (and its elements) is used as a source of metaphor for describing all the spheres and domains of human activity. The prerequisites for the man-tree metaphor are the qualities of man and tree which can be matched: the physical configuration of the tree and the human body, which is vertically directed; local relations between trees and human relations; the visual image of the tree and the family tree concept. The cultural concept of the tree is implicit in personal names and idioms as lexical units. It manifests itself in the context of folklore texts (rhymes, ballads, verbalized superstitions, incantations, riddles) and classical works of fiction. The man-tree metaphor reflects the ancient ideas about man-tree kinship and man-tree isomorphism. The metaphorical transfer is reciprocal: the man can be endowed with the qualities of the tree, the tree can be endowed with the qualities of the man. The man-tree / tree-man metaphor is based both on the generic concept of the tree and its elements and on the concept of individual trees. The man-tree metaphors are verbalized through nouns (functions and status), verbs (activities), adjectives (qualities).
\end{abstract}

\section{Introduction}

Man-tree relations are predominantly an issue of biological studies. These relations are also researched into from the utilitarian perspectives, where the main concern is the role of tree in human life. Trees provide shelter, food, clothes, fuel, wood and tools. Meanwhile trees have acquired symbolic functions reflected in language in the form of metaphors, which have been frequently used as theses for expressing nationalistic feelings or national identity.

The Russian historian V. Klyuchevskiy argued that Man began to cognize and explore the world from viewing and exploring the nearby natural objects, which formed an environment as part of human life and activity [1]. Furthermore, Klyuchevskiy highlights the specific role of forests which function as an economic, political and moral force and are capable of replacing mountains, castles and providing strong defence from external enemy [1], which is explicit in the language. Thus, ethnic identity is directly related to the people's environment, which encompasses forests and trees. Western civilization started and developed with clearing areas from forests. The borderlines between forests and clearings functioned as starting points of civilization. There is a strong opinion that cultural and social phenomena (religion, family, town, law etc.) were developed to oppose Man with nature and forests, which fell victim to Man eventually [2].

\footnotetext{
*Corresponding author: abramel@mail.ru
} 
The long history of man-tree relations forced and enabled man to cognize nature, to explain natural phenomena and objects, endow them with human and divine traits. This gave rise to totemism as the ideology of primeval tribal society and the basis for all European customs [3], which can currently be traced in the language functioning as a keeper and translator of previously acquired knowledge and developed ideas.

The research presents the tree as a source of metaphor for describing man, human body, human personality, family structure, man's social functions, relations with other people. These age-old metaphors, on the one hand, come as a result of man's observation of trees, comparison, categorization and on the whole as a result of human cognitive activity. We are also interested in the principle of metaphorization of the tree in language and culture as a way of cognition of this natural object in ancient times. On the other hand, the tree metaphor presents historical data and facts, which are to be decoded through the recipient's knowledge of the cultural image of the tree. If the recipient's knowledge is not sufficient or relevant, the implicit original meaning of the metaphor tends to be lost. Therefore, the topicality of the research is related to the ecological attitude to trees and the ecological trend in linguistics.

The objective of the paper is to analyse the principles of man-tree / tree-man metaphorization by the example of the generic lexeme tree, and individual tree names (also known as dendronyms) oak, thorn, ash, willow (withy), birch, yew, elm, ivy, holly, beech, mistletoe and others. The approach to the analysis is to collate them with their referents in European, Celtic, English and modern British cultures. We aim to determine how the tree fits into traditional culture, how man and tree correlate, and how these views and relations are metaphorically reflected in the English language.

\section{Methods}

Tree is one of the major metaphors in all cultures and it is used to describe and present all spheres of human activity and all kinds of human interaction.

The object of the research is the language units verbalizing species of trees, and belles lettres and folklore texts illustrating metaphorical links between man and tree. The correlation between the tree name (dendronym) and the tree concept (dendro-image) develop in the following way: the tree concept is culturally based; the tree name is an element of language. The existing tree concept affects the functioning of the tree name. The compliance of the tree name and the tree concept occurs in the following linguistic domains: personal names, idioms, folklore texts (rhymes, ballads, superstitions, riddles, incantations), classical fiction. These data will be used as the input for the cognitive analysis.

Man-tree isomorphism becomes elicit in personal names which frequently reflect ancient pagan ideas of man-tree kinship, according to which the tribe chieftain traces his origin to the tribe tree, and the qualities of the tree correlate with the human personality. On the whole, personal names are important lexical components both of the language world view and of the phytonymic code of culture. Personal names contain information encoded centuries ago, which enables researchers to trace the history of ethnical ideas and concepts reflected in the language. Thus, personal names are culture encoding signs [4].

We also aim to analyse idioms as treasurers of information and culture, reflecting ancient views of nature. They present linguistic results of human observation of trees: their physical configuration, behaviour, qualities, functions, interaction of trees in physical and cultural arboretum. These criteria are applied to man as well, thus, tree is compared to man. Idioms are viewed as the memorial aggregation of past events and as intangible cultural and historical heritage [5]. We argue that the metaphorical potential of the tree can be made explicit through analysing idioms, their etymology and original meaning.

We also research into folklore texts, including ballads, songs, children's rhymes, verbalized superstitions, in which trees are likened to human beings and function as 
characters. Their functioning, behaviour, activity, symbolic concepts metaphorically reflect or prescribe patterns of human behaviour, which have been worked out for centuries.

We discuss classical works of fiction, in which trees, tree concepts or tree names perform an important role in the plot development or the author's message, and trees function as the characters. The plot or the characters allude to the symbolic functions of the tree, its role and place in English arboretum, which is metaphorically compatible to man's function and role in human society. We analyse tree metaphors from works by E. Spenser, W. Shakespeare, W. Scott, R. Southey, R. Burns, Th. Gray, A. Tennison, M. Hewitt, O. Wilde, E. Bronte, J. R. Tolkien etc. to identify the ways of metaphorization, the cultural base of the metaphor and trends and tendencies of tree metaphorization in British culture and the English language. We eliminate lexical units (verbs, nouns, adjectives, adverbs), which are subjected to metaphorical transfer in the tree-man framework.

\section{Results}

The research into man-tree / tree-man metaphor has resulted in the following theses:

1. Although the tree is a biological object and an element of nature, it is also a component of the cultural code and it possesses a set of cultural meanings, which have developed for centuries.

2. The metaphorization of the dendronym in the language is based on the metaphorization of the tree in the corresponding culture.

3. The tree metaphor is convenient because the tree and its elements (bark, trunk, leaf, branch, bough etc.) are used to describe all the spheres and domains of human activity. We argue that the principles of tree metaphorization are similar in different cultures, which reflects the commonality of world views and the tree concept.

4. The cultural concept of the tree is implicit in personal names and idioms as lexical units. It manifests itself in the context of folklore texts (rhymes, ballads, verbalized superstitions, incantations, riddles) and classical works of fiction.

5. The man-tree metaphor reflects the ancient ideas about man-tree kinship. The mantree metaphor is conditioned by man-tree isomorphism. The prerequisites for the man-tree metaphor are the following qualities of man and tree which can be matched: the physical configuration of the tree and the human body, which is vertically directed; local relations between trees and human relations; the visual image of the tree and the family tree concept. The tree, according to its topographic and local position and arrangement, its function, structure and appearance, is endowed with gender and professional characteristics.

6. The metaphorical transfer is reciprocal: the man can be endowed with the qualities of the tree, the tree can be endowed with the qualities of the man.

7. The man-tree / tree-man metaphor is based both on the generic concept of the tree and its elements and on the concept of individual trees. The oak as a masculine tree is the metaphor for a brave man, an English sailor, the King, and an old man. The birch is a feminine tree in English culture and symbolizes the beginning of life. One of the metaphors for the birch is the Lady of the Wood. The ash has a feminine hypostasis, but it is a warrior. The willow is a flexible person, a grieving person, and a slender woman. The elm is a malicious person. But together with the vine the elm is one of the loving couple or the husband, while the vine is the wife. The yew is the guardian of the grave. The beech in its feminine hypostasis is the queen of the wood and its function is to protect the family, the loving couple and the young. The holly and the ivy in British literature and folklore represent the masculine and the feminine creatures. The above-mentioned metaphors are verbalized through nouns (describing functions and status), verbs (describing activities), adjectives (describing qualities). 


\section{Discussion}

In this section of the research, we will describe the cultural and historical conditionality of man-tree / tree-man metaphor and the parameters of the man-tree compatibility. We argue that the man-tree metaphorization is the result of the human attempt to conceive and explain natural phenomena, which the ancient man observed, and natural objects, which he came in contact with on a daily basis.

The man-tree comparison in British culture, which is traced back to Indo-European ideas and concepts, was fully developed in Celtic times. The Celtic mythology abounds in cases of man-tree isomorphism. The word 'druid' etymologically refers to the Celtic name of the oak, therefore druids chose oaks and mistletoes, the unfailing companions, for their spiritual and social ceremonies and rituals. The inauguration of the tribe chieftain was performed in the oak grove, which was thought to impart the attributes and qualities of the oak to the chieftain: wisdom, greatness, and mightiness. These ideas were developed in Welsh mythology, literature and folklore. As is known, Blodeuwedd, a character of the Welsh mythology 'The Mabinogi', is created from the flowers of the broom, meadowsweet and oak. King Arthur's brother Kay strives to grow as tall as the tallest tree and to equal the tree in power and size.

The author of the medieval Welsh manuscript of the XIV century Cad Goddeu/ The Battle of the Trees (the Llyfr Taliesi series), recorded from oral myths and tales, describes a battle fought by trees and bushes against the enemy. The magician Gwydion (the name can be interpreted as 'born of trees') animated the trees and endowed them with human qualities. The first blow was delivered by the alder. Then the rowan and the willow joined the battle followed by the blood-thirsty and prickly thorn-tree, the skilled loquat, the ivy, soft but boisterous in the battle, the noble birch, the thistle, courageous in the battle. The ash fought heroically, the elm delivered blows right and left, the white thorn inflicted fostering wounds, and the screams of the oak made the earth and the sky shake. The metaphors the author used in the text testify to the ideas of man-tree isomorphism. The author introduced metaphors to describe the behaviour of the trees in the battle according to the qualities and functions of each species. The elm is known to throw off its heavy branches unexpectedly even in windless weather. In the battle the elm delivers blows in all directions. Thorn-trees and whitethorns are described as blood-thirsty and inflicting fostering wounds because of their thorns etc.

The Celts also used the tree metaphor for describing human thought, which extends and outspreads like branches of a tree. In this case the visual image of a tree correlates with the one of the human activities [6].

We will dwell on the major parameters of man-tree compatibility: the structural similarity of the human body and the tree, the analogy of social structure and the visual image of a tree, interaction between species of trees and human relations, biological life and transformation of a tree and its functions and human life.

Firstly, the man-tree compatibility is based on the multivalency and some structural similarity of their physical bodies: the human trunk and the trunk of the tree, the arms and the branches, the human head and the tree crown. This compatibility gave rise to the idea of man-tree kinship. Thus, in human sacrifice rituals the tree was frequently committed to flames instead of the human being. Furthermore, Celtic family names or first names were derived from the names of the trees with the Mac/ Dar prefix added: Mac Daro - son of the oak, Mac/ Dar Charithinn - son / daughter of the rowan, Mac Cuill - son of the hazel, Mac Dreign - son of the thorn-tree, Mac/ Dar Ibair - son / daughter of the yew etc. [6]. It is assumed that such family names reflect the ancient Celtic tradition, when clans chose and worshipped their sacred trees and believed that the clan originated from that tree [7]. It must be pointed out that the physical structure and functions of the tree are used as metaphors not 
only for human body, but primarily for human personality. For example, the 'tree - human personality' metaphor is abundant in English poetry [8].

In whole, Europeans have long had a pious opinion that humans originated from trees and that after they died their souls were put into trees for eternal keeping. Old Germans worshipped the ash because they believed they had originated from the ash which was the first human creature. According to Old German and Scandinavian mythology (The Prose Edda) the gods Odin, Loddur and Honir found two small trees by the sea, out of which they made the parents of the human race and "gave them spirit and life, wit and feeling, form, speech, hearing and sight". The first creatures were called Askr (English ash, German Esche) and Embla (English elm, German Ulme) [9]. So, Scandinavians and Old Germans believed that man and tree are related to each other. Helgi, a hero from Scandinavian sagas, who also appears in 'The Poetic Edda' is compared to a noble ash, and the warriors are compared to the briar, he towers over.

The eloquent proof of man-tree relation is the anthroponymic system of the English language, which indicates man-tree isomorphism, similarity of their physical structures, ideas of the spiritual life of the tree and of the human qualities, which the tree possesses. The Old English practice of name giving provides ample proof that appellative lexemes were borrowed from semantic arboretum and were implemented as personal names. We argue that the metaphoric transfer was conditioned not only by the phonetic euphony of the lexeme but also by the positive cultural connotation and semantics of the dendronym as a common noun.

In the Old English practice of name giving the appellative lexeme wid $(d)$ a (willow, dialectal) functioned as an anthroponym. Later, at the end of the XX century, there developed a tendency in the USA and Great Britain to use personal names with explicit semantics originating from appellative nouns, which included tree names as well [10]. For example, the name Hazel is still popular, moreover, its popularity is still growing. The male name Holly lost its popularity in the mid-XX century and was replaced with its female variant. It must be noted that the name is granted mostly to the girls born at Christmas time. It testifies to the fact that the name has a cultural and symbolic background and phytonymic associations, which English speakers are still aware of. The female name Willlow is slowly increasing its popularity compared with its male variant. Rowan is on the list of 100 top personal names in Great Britain, both as a male and female name. The Irish-language counterpart of the name Rowan has always been popular as well. The other dendronyms which function as anthroponyms are Linden, Myrtle and Juniper [10]. The compound personal names with a dendronym component have been used for centuries. Both the female and male compound name Ashley (from Old English cesc - ash and le ah - meadow) has been popular since the XVI century. The name Lindsey with the linden-related component is famous due to American actress Lindsey Lohan.

The ideas of man-tree isomorphism inherited from Celtic culture are reflected in English family names, like Oak (625 individuals). Oakes (10134) from MacDarragh, Oaks (125), Oakey (1623), Oakley (15692) [11]. The practice of acquiring English family names developed on a large scale in the times of King John Lackland. The family names with a dendronymic component were borrowed or derived from the names of the trees which were either the landmarks or the specific features of the farms or estates where the name bearers resided. That was the case of both metaphoric and metonymic transfer from the tree nomination to the nomination of the farm owner, based on earlier ideas of man-tree isomorphism,

Secondly, the tree correlates not only with an individual person but with the whole family. The concept Family tree originally referred only to Jesus Christ's genealogy. Later it was transferred by Giovanni Boccaccio onto other gods. Presently the term is applicable to the genealogy of any individual. The metaphor tree of life has multiple meanings. In mythology the tree of life underlies the image of the Biblical paradise tree and the sacred tree of the 
people. In philosophy the concept 'tree of life' highlights mutual connection and common biological background of all living species. In biology the tree of life is synonymous with the phylogenetic tree.

In European culture human loneliness is associated with the tree without branches or roots. The following man-tree metaphors illustrate this. Children murdered by mothers are metaphorized through shoots without roots. The father separated from his sons is compared with the tree, whose roots are hewed, and whose trunk is deprived of branches and twigs. The mother who has lost her daughter is similar to the tree without foliage or branches [12]. Anglo-Saxon paganism is rooted in nature, the important part of which is trees. The cult of sacred trees was harmoniously embedded into Christian world views. Up to the Victorian times there was a popular belief in English society concerning the relations between the tree and the family, predominantly a noble family. If the tree lost its branch, which fell off or withered, the head of the family was expected to die shortly afterwards. To prevent the death of the lord the family propped up or tied up the dead branch. Mostly the oak, the elm or the cedar were viewed as family or clan trees. An interesting episode related to the death of George Carnarvon, who discovered Tutankhamun's tomb, illustrates the above-described views. Following the message of his death, crowds of people fled to his house to see whether a branch fell off their family cedar [13].

Thirdly, botanical and locational interaction between trees were transferred onto human relations. For example, the metaphor of man-woman relationship is based on the interaction between the oak and the mistletoe. It has been used in English literature and is verbalized through the verbs entwine and hug, describing the actions characteristic of human beings. Furthermore, the two major European complexes of the ethnic cult trees, the oak and the birch, possess the male and the female hypostases. The oak is associated with power and thunder as male attributes. The birch symbolically signifies femininity and the start of life.

Fourthly, the life cycle of the tree is metaphorized as well. The tree metaphor is of productive character because all the stages of human life undergo metaphorization: conception, growing, puberty, maturity, ageing, death. The human being like the tree is conceived from seed [14]. Cardinal Wolsey, a character from Shakespeare's play 'Henry VIII' bears hatred and mockery with fortitude. When left alone, he gives a soliloquy about his bygone power and greatness. The monologue is based on the man-tree metaphor, which is frequently implemented in English poetry: in his youth Wolsey compares himself to a plant with 'tender leaves of hope', then the man 'blossoms' and 'bears his blushing honors' upon him, the moment the man is sure 'his greatness is a-ripening', 'a killing frost' 'nips his root', 'and it falls as I do' (III, 2) [8].

The tree is one of the major metaphors used in all cultures, because its functions, visual image, quality of wood, behaviour may be applied to describe metaphorically various spheres of human life. The complex structure of the tree and its parts (roots, branches, bark, trunk, foliage, flowers) are the base for various metonymic and metaphoric transfer to describe a human being as a personality and a social structure of human society. The root of the tree is the metaphor for the origin, beginnings, and the past; the trunk is the major quality of human personality; the branches and leaves are the fruit, breed, results; the branches also symbolize movement, spread, extension; the bark is the metaphor for the integral entity. The visual image of the tree serves as the metaphor for a family, not only a human family, but also a language family.

The semantic and cultural analysis of the idioms with the tree-component provides a complex concept of the tree and its role in human life. The tree as inner human essence becomes explicit in the idiom out of (one's) tree 'crazy and untypical behaviour' and shake (one's) tree 'stimulate, urge smb to do smth'. A similar meaning can be found in the proverb the apple doesn't fall/never falls far from the tree 'behaves like the others members in the family', where the human family is compared to a tree. The same principle underlies the 
phrase family tree, where family genealogical and social ties and relations are visualized in the structure of the tree.

The practical usefulness and functionality of the tree is explicit in the proverb a tree is known by its fruit (, a man by his deeds). The first part of the proverb is a metaphor with implicit meaning. The full variant is an explicit comparison with a parallel structure. The tree and climbing the tree are associated with labour, the fruit of the tree is the metaphor for the result of human activity: he that would eat the fruit must climb the tree. The idiom live in a tree 'have good luck' implies wealth and protection the tree provides for the man.

In the following idioms the tree metaphorically describes situations and people's attitude to them: bark up the wrong tree (1820) 'be wrong about smb or smth on the way to achieve smth' (sphere of hunting), cannot see the wood/ forest for the trees 'be unable to understand the situation clearly'. The idioms in which the tree correlates with the life cycle and professional growth of the man belong to this group as well: at the top of the tree 'reach the highest level of one's career or life', every/a monkey knows what tree to climb 'being a professional, being able to understand the situation'.

The metaphorical phrase tree hugger 'tree ecologist' implies people's caring attitude to forests and trees. The origin of the phrase a partridge in a pear tree is related to ideas of Christianity.

The proverb As the twig is bent, so is the tree inclined metaphorically implies a human being (the tree) and their ability to be flexible like a small twig. The physical configuration of a flowering green tree testifies to its health and power, which is verbalized in the idiom flourish like a green bay tree 'to prosper'. Meanwhile the idiom Christmas tree implies a drunken person, who attracts everyone's attention with their appearance and behaviour, and in this way the person is compared to a bright Christmas tree.

The foliage is the most attractive, dominant, and decorative part of the tree. Therefore, there is ample material for metaphorization. In this paragraph we will discuss a group of metaphors based on foliage and leaves. The shape, size, and colour of leaves, function of foliage, movement of leaves in quiet and windy weather, their precedent role can be found in different idioms, which describe a human being, their personality and behaviour. The base for metaphorization is the parallel between the tree and a small world, where a person (a leaf) lives. The leaf also serves as a metaphor for a stage in human life and samples of behaviour to observe and to follow, which is implicit in the following idioms: turn over a new leaf 'start a new period in life', take a leaf out of somebody's book 'imitate smb's bejaviour'. These idioms constitute a triple metaphorical chain: the tree and its leaf, which are compatible to a book (paper is made from wood) and its page, which is transferred onto human life and a period in it. The movement of the leaf in the wind is the metaphor for human behaviour in a difficult situation: quake/ shake like a leaf, or quake/ shake like an aspen leaf (Christian association).

Then we will consider metaphors based on individual trees and tree names. The fact that these idioms have been used for centuries is the evidence of ancient ideas of man-tree isomorphism, which was rooted in Indo-European culture and has been developed in British culture and the English language.

The Oak in the man-tree metaphor.

The oak has a male hypostasis in British lingvoculture, therefore the tree name is used mostly in metaphors implying masculineness.

The metaphor for English seamen heart of oak was the principal element in the concept of English identity and in expressing nationalistic feelings. The following metaphors describe a strong person: An oak is not felled by one blow/at one chop/at one stroke. Great oaks (are) hewn down with many blows. The metaphors for a rigid, inflexible person are Many strokes overthrow the tallest oak. Little strokes fell great oaks. The smallest axe may fell the largest oak. Long ere you cut down an oak with a penknife. 
A mighty oak grows out of a small acorn and develops for years. This metamorphosis serves as a metaphor in the following idioms: Great oaks from little acorns grow. An acorn one day proves an oak. The greatest oaks have been little acorns. Every oak has been/must be an acorn. To develop into a mighty tree and to bear fruit the oak has to have powerful roots, which is implicit in the idioms, describing the growth of the oak from an acorn to a mighty tree: Today's mighty oak is yesterday's little nut that held its ground.

The oak is a metaphor for a wise and old person, who has lived a long and worthy life. Robert Southey described the oak as the embodiment of respectable old age and the object of respect: Lovely is the age Of virtue: with such reverence we behold The silver hairs of some gray oak grown old. Southey draws the reader's attention to the foliage of the oak: stately head of the oak, comparing it with the grey hair of an old man.

The oak metaphor is frequently used in the famous Works of Ossian, actually written in the style of Gaelic legends by James Macpherson in Scotland in the XVIII century. The author used the metaphor to describe the emotional state and situations the characters find themselves in, which is both man-tree isomorphism and similes.

For example, Malvina, mourning her beloved Oscar, compares herself with the oak: but thy death came like a blast from the desert, and laid my green head low. The spring returned with its showers; but no leaf of mine arose.

Another metaphor is used to describe the death of Rino (Ryno): They have fallen like the oak of the desert; when it lies across a stream, and withers in the wind of the mountain. The characteristic feature of the poem is the idea of man-oak isomorphism: the foliage is the head of a proud person, the rusile of the leaves is compared to a human voice, the fog covering the oak symbolizes clothes, which hides the oak from the outside world. The oak with its rough bark not covered by leaves is the embodiment of an old person.

The poetic book for children compiled by M. Gurney includes a poem describing the oak as the paragon for children's behaviour: Yes, try, my dear child, to be good, to be wise, And then you will find, if to manhood you rise, You'll be valued and prized like the oak. The author highlights the following status qualities of the oak, which children should respect and follow: wisdom, mightiness, nobleness, exclusiveness - the pride of our forest, majestic, nobly, gallantly, strong, stout.

The classical example of man-oak isomorphism in English poetry is the poem The Oak by Alfred Tennison. The biological life of the oak is the metaphor for human biological and social life. The young oak is bright and living gold in spring. Like the young oak the man is full of energy and movement in his youth. With the fleeing of the seasons the oak changes. In summer the oak is rich in flowers and fruit, which is the metaphor for the man's maturity, when the man is rich in what he has achieved by his mature age. In autumn the oak is gold again but it soberer-hued gold, which metaphorically describes the wisdom and experience the man has acquired. Then the oak loses its leaves, which are the metaphor for the man's power, and becomes weaker physically, but the power of the oak and the man is in the wisdom, knowledge, reasoning and inner strength (trunk - personality), which becomes naked after the leaves have fallen off, but more visible.

The longevity of the oak provides a metaphor for nominating old people. On the other hand, the old man is the metaphor for the ancient oak. Man-oak isomorphism can be found in the names of some oak in the English countryside, for example, The Old Man of Calke in the county of Derbyshire.

We will consider another example of man-oak metaphor in poetry. Edmund Spenser, the English poet of the XVI century and Shakespeare's predecessor, described the quintessence of the oak in his work The Shepherd's Calendar (in the eclogue February), using the manoak comparison: the oak is the King of the Field, the oak larded many swine. The oak is described through man-metaphors as having arms instead of boughs: full strong arm, big and mightily pight body, bald top. The oak performs a human-related function of the king. The 
oak has honor, which has decayed. In whole, the author used traditional allusions to the oak, the quintessence of the British attitude to the oak: the oak is an old person, the oak is the king, the oak is a labourer.

The traditional lexemes for describing the oak in English literature are stiff-necked British oak; brave; nobly; gallantly; wise. Traditional metaphors to describe the behaviour and the functions of the oak are builder; His honor; the King of the field; warrior oak; Friend for an ivy; a sceptre for England; the queen of the sea; monarch of the forest; Giant.

The Willow in the man-tree metaphor.

We will consider two man-tree metaphors including the willow-component, which are based on the flexibility of the tree viewed negatively or positively. A flexible person, open to new views and situations is described in the following proverb: Willows are weak, yet they bind otherwood. The next phrase has a negative connotation: Willow in the wind, which characterizes a person, whose views and opinions often change under the influence of other people or in different circumstances. The phrase alludes to the behaviour of the willow in the wind. Like a willow in the wind a person is not able to keep to their opinion and hesitates over a choice. On the other hand, the phrase has a positive connotation, if the willow is used to characterize a slender, slim or graceful person: Despite her age, she was graceful as a willow in the wind. The simile as slim as a willow implies that the willow is categorized as a female tree. The idioms thin as a willow rod, bend like a willow, pliant as a hoop-willow, limmock as a willow stick indicate the main quality of the willow, the symbol of flexibility, pliability and slimness. Although the idioms are obsolete and dialectal, they reflect the ancient ideas and superstitions of the qualities of the willow. The pliability of the willow can be interpreted differently in the idioms dour/ stiff/ thrawn/tough as a withy, implying people's obstinacy and rigidness of objects.

The Birch in the man-tree metaphor.

The birch possesses a female hypostasis, which is verbalized in the metaphor Lady of the Woods. The metaphor was first used by Samuel Coleridge, who modified the obsolete phrase the damsel of the wood, and is still common in English poetry. The alleged feminine qualities of the birch are the white bark, the slender trunk, and occasionally the form of the foliage interpreted as weeping. Thus, the metaphors and epithets used for the birch are the verbs and adjectives describing mostly examples of women's behaviour (weeps in fragrant balm; weaves her crown) and women's appearance (graceful; weeping). When leaves fall off the birch it looks 'naked' in winter due to its white bark. This gave rise to a number of idioms: As bare as a birch in December / at Christams / at Yule event, which metaphorically describe a person who is purged of the negative impact or poor like a birch without clothes.

The Elm in the man-tree metaphor.

The man-elm isomorphism is conditioned by the size of the tree. Therefore, J. R. Tolkien used the elm as a criterium for the giant. On the other hand, the elm is regularly compared with an old man: a line of old elm trees like old men ambling across (Ottoline Morell). Elms old men with thinned-out hair, and mouths down-turned, express the oldness of the English scene (Geoffrey Grigson). The following metaphors describe the movement of the leaves and boughs in the breeze and interpret the sound as the voice of the elm: whispered loftily, was singing. The parts of the tree, interaction with other trees and plants, throwing off boughs are interpreted through man-related metaphors: barky fingers of the elm; wedded to the vine; hating mankind (when the elm unexpectedly throws off heavy boughs even in quiet weather).

The Beech in the man-tree metaphor.

Man-beech isomorphism in fiction is reflected in ascribing to the beech human qualities like a human voice, human feelings, human functions, or describing the beech in terms of human body, thus ascribing femininity. For example. Thomas Hardy describes the voice of the beech in the novel Under the Greenwood Tree in comparison with the voices of other trees, highlighting its individuality, which is not destroyed by winter: rustling, chanting, 
wailing. Then Hardy describes the beech in the man-tree metaphors, endowing the tree with human qualities and features: Above stretched an old beech, with vast armpits, and great pocket-holes in its sides where branches had been amputated in past times. To describe the human-like feelings the tree experiences, the author uses colour metaphors. For instance, when the beech is indifferent to human sufferings, it is pale grey. The crown of the beech is compared to a veil: High beeches, bending, hang a veil of boughs, And sweep against the roof (Th.Hardy Domicilium). The beech, being the queen of the wood, interacts with the oak, the king of the wood: light beech embraced by the oak.

The Ash in the man-tree metaphor.

The Ash is alleged to have been one of the parents of mankind according to Old German mythology, which provides the base for the following man-tree metaphors, describing the actions and functions: the ash drinks the stream with vigour; has a diadem; spreads his diadem to shield something. The ash is also known as the cradle of life; husbandman's tree; the ash for nothing ill. The young ash is the metaphor for a young girl: She's stately like yon youthful ash. This is how Robert Burns describes his beloved Alison Bagby.

The Ivy in the man-tree metaphor.

According to mediaeval concepts the ivy had a female hypostasis, which was conditioned by its flexibility and ability to enwind other trees. Botanically the ivy as a parasite tree and has to entwine the neighbouring tree to survive. But this ability was culturally interpreted as embracing, hugging, loving, being faithful and loyal. This ability can be of positive or negative character, which is illustrated with the following examples: the ivy is female, usurping, clasping, joyless. The ivy enrings, creeps, steals, crawls, scratches its underlying neighbour restlessly, and even strangled to death the promising sapling. Most of the mentioned metaphors describe the relation between the ivy and other trees, the ivy relies on, but the ivy is mostly interpreted as a negative character. Thus, in one of Shakespeare's last plays The Tempest, Prospero, the rightful duke of Milan, cast from the throne by his brother, compares him with the ivy: The ivy, which had hid my princely trunk, And suck'd my verdure out on't. Shakespeare endows the ivy with a male nature, because of the way the ivy affects other trees and defeats them. The ivy symbolizes treachery in this play.

Other trees in the man-tree metaphor.

We will illustrate other dendronyms used in the man-tree metaphors with single examples.

The holly was first mentioned in literature in carols related to the times of Henry VI's reign. Mostly the holly is described together with the ivy but in contrast to it: the ivy is a female tree due to its flexibility, the holly is a male tree because of its thorns. The ivy attracts only owls, the holly attracts all species of birds, so the fact is interpreted in terms of the personality of the holly, which is viewed as a jolly tree: The holly whistles as it battles with itself.

Shakespeare writes about women's meaning of life in terms of thorn metaphors. A married woman is compared with a rose on a thorn-tree, enjoying her life with her family in spite of the challenges of her life. The spinster is described as a thorn-bough, displaying her bristly character.

Other writers also use thorn metaphors to interpret vividly different kinds of human relations. Emily Bronte describes the relations between Katherine and Linton in the novel Wuthering Heights in botanical terms to highlight whose love was stronger, and the personalities of the beloved couple: It was not the thorn bending to the honeysuckles, but the honeysuckles embracing the thorn.

The yew is described as a stubborn person, withering with age. It is often interpreted as a lonely tree associated with death. 


\section{Conclusion}

The contrast between nature and culture becomes less vivid when elements of nature are interpreted in cultural terms and acquire cultural value. The tree was incorporated into human culture and social interaction and was interpreted as compatible with a human being and their personality. The tree was endowed with feelings, relations, human social functions. These ideas are viewed as valid, they are maintained and developed in human society. These concepts become recognizable and accepted signs in language and culture, either universal or culturally specific. Therefore, the tree as a concept developed from a botanical object to a cultural phenomenon. The human being has always coexisted with the tree, observed its growth, development, behaviour, role and function in natural environment, and thus the human being developed its cognitive abilities trying to explain natural phenomena related to the tree comparing them with human phenomena and with themselves, as the most familiar and cognized in the natural surroundings. This comparison is reflected in fixed and free metaphors in language (anthroponyms, idioms) and culture (folklore, literature). Language expressive means reflect this cognitive process, thus connecting the man and the tree.

Undoubtedly, the man needs the tree as the source of shelter, food, tools, household utensils, cult objects, and as a source of cultural and linguistic metaphor. However, it is precisely the human civilization, which caused the greatest damage to trees. The conservation of forests and trees has linguistic and cultural value as well, as it enables people to preserve meanings and implications in language and culture. Despite felling and clearing, the history of trees continues. It is incorporated in human history, it reflects human ideas, views, aspirations, dreams, apprehension, and passion [15].

Ancient views about animated and human-like trees have been researched into and developed nowadays in phytosociology, a new branch of science, which proceeds from the thesis that vegetal life is compatible with human life and society [16], and in linguistic ecology which addresses the issues of interaction between human beings, language and trees as a part of the environment. In whole, views on man-tree isomorphism are preserved in language, its idioms and anthroponyms, folklore, poetry, prose which describe various aspects of modern life.

\section{References}

1. V.O. Klyuchevskiy, Russian history. Articles (Moscow, ASI: Astrel', 2003)

2. R.P. Harrison, Forests: The Shadow of Civilization (University of Chicago Press, 2009)

3. D.K. Zelenin, Ethnographic series 5 (1937)

4. G. Lukash, Semantics of language and text (Ivano-Frankivs'k, 2006)

5. T.I. Skorobogatova. O.Yu Suraleva, Herald of South Federal University. Philology 4 (2016)

6. S. Heinz, Celtic Symbols (New York, Sterling Publishing Company, 2008)

7. R. Bevan-Jones, The Ancient Yew: A History of Taxus baccata (Oxford, Windgather Press, 2016).

8. V.P. Komarova, Metaphors and allegories in Shakespeare's works (Leningrad, Leningrad State University, 1989)

9. J.A. MacCulloch, The Celtic and Scandinavian Religions (Chicago, Academy Chicago Publishers, 2005)

10. T.A Komova. S.I. Garagulya, Personal name in English-language cultural and historical space (Moscow, Linrokom, 2012) 
11. British surnames, http://britishsurnames.co.uk/surnames/OAK

12. T.V. Toporova, Issues of onomastics 5 (2008)

13. E. Kouty, Superstitions of Victorian England (Moscow, Tsentrpoligraf, 2011)

14. O.V. Dekhnich, Bulletin RUDN. Issues of Education: languages and specialty 3 (2009)

15. N. Shtil'mark, Mysterious lives of trees. What they feel, how they communicate (Moscow, Hogher School of Economics, 2019).

16. P. Vol'leben, Mysterious lives of trees. What they feel, how they communicate (Moscow, Hogher School of Economics, 2019) 